\title{
Paris und das Klima
}

\section{Liebe Leserin, lieber Leser,}

der Vertrag kann greifen. Um nicht länger als Bremser dazustehen, hat das EU-Parlament in Windeseile das Pariser Abkommen zum Klimaschutz ratifiziert. Selten haben die europäischen und nationalen Bürokratien so schnell und zielorientiert gearbeitet. So konnte der internationale Vertrag am 7. November 2016 in Kraft treten und auf der zugleich stattfindenden UN-Folgekonferenz im marokkanischen Marrakesch gefeiert werden. Länder, die nicht gerade als Klimaretter bekannt sind, wie China, Indien, Mexiko, die USA und über 60 andere Staaten, waren vorgeprescht, die globale Erwärmung auf deutlich unter $2{ }^{\circ} \mathrm{C}$ im Vergleich zum vorindustriellen Niveau zu begrenzen. Damit wurde das erste Kriterium schnell erreicht, dass mindestens 55 Staaten ratifizieren müssen. Durch die Unterschrift der EU wurde nun auch das zweite Kriterium erfüllt. Denn die Unterzeichner müssen für wenigstens $55 \%$ des weltweiten Ausstoßes an Treibhausgasen stehen. Die EU verantwortet etwa $12 \%$ der $\mathrm{CO}_{2}$-Emission, möchte diesen Wert unter anderem mit der Förderung der Elektromobilität weit nach unten drücken.

Mit „Paris“ haben sich viele kleinere Staaten zum ersten Mal überhaupt Klimaziele gesetzt. Wie die Frankfurter Rundschau berichtet, bietet Deutschland ihnen technische Hilfe an, wie $\mathrm{CO}_{2}$-Einsparungen erreicht und überprüft werden können. „Wir wollen diese Staaten in die Lage versetzen, ein transparentes $\mathrm{CO}_{2}$-Monitoring aufzubauen“, erklärte Nicole Wilke, Klimadiplomatin des Bundesumweltministeriums, in Berlin.

Ein positives Beispiel ist hier Marokko, das bisher $95 \%$ seines wachsenden Energiebedarfs mit fossilen, zugekauften Energieträgern erzeugt und neue Wege gehen will. Erst im Februar hatte König
Mohammed VI. den ersten Teil einer Großsolaranlage eingeweiht, drei weitere folgen. Mit dem Solarpark „Noor 1“ setzte die marokkanische Agentur für Solarenergie „Masen“ in nur zweieinhalb Jahren eine Anlage mit über 500.000 Spiegeln in die Wüste bei Ouarzazate. Das reicht laut FAZ, um mit dem 160-MWSolarkraftwerk 350.000 Einwohner mit Strom zu versorgen. Schon bald will der jetzige Energieimporteur grünen Strom nach Europa exportieren.

Schön wäre, wenn unsere deutschen Stadtwerke und Energieversorger ebenso auf erneuerbare Energien setzen, damit die Elektromobilität wirklich $\mathrm{CO}_{2}$-neutral wird. Dass nun beschlossen wurde, den $\mathrm{CO}_{2}$-Ausstoß deutscher Kraftwerke bis 2050 lediglich zu halbieren, ist nicht gerade zielführend. Und so manchen Käufer dürfte es auch deshalb von einem Elektroauto-Kauf abhalten, weil der deutsche Strommix immer noch von Kohle dominiert wird. Ein solches E-MobilitätsProjekt der Stadt Bad Homburg stellen wir Ihnen ab Seite 8 vor.

Herzliche Grüße, Ihr

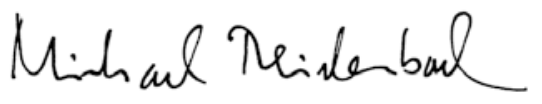

Dipl.-Ing. Michael Reichenbach Stellvertretender Chefredakteur

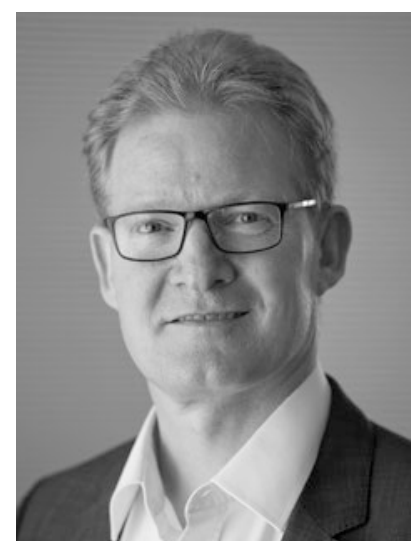

\section{Mehr PS per Maus- klick?}

Over-the-Air (OTA) liefert frei Haus.

After-Sales 2.0: Software-Updates und neue Fahrzeugfunktionen werden nicht mehr in der Werkstatt aufgespielt, sondern bequem von zu Hause aus bestellt. Um diese Vision wahr werden zu lassen, bieten wir eine Ende-zu-Ende Lösung für sichere Übertragung von der Cloud ins Fahrzeug. Wichtigstes Qualitätsmerkmal? Die Firmware-over-the-AirAnwendung und deren Integration erfüllen dabei alle Anforderungen an Safety und Cyber Security. Nur tanken müssen Sie selbst. Noch.

ITK Engineering AG - Ihr Partner für sichere Vernetzung.

www.itk-engineering.de

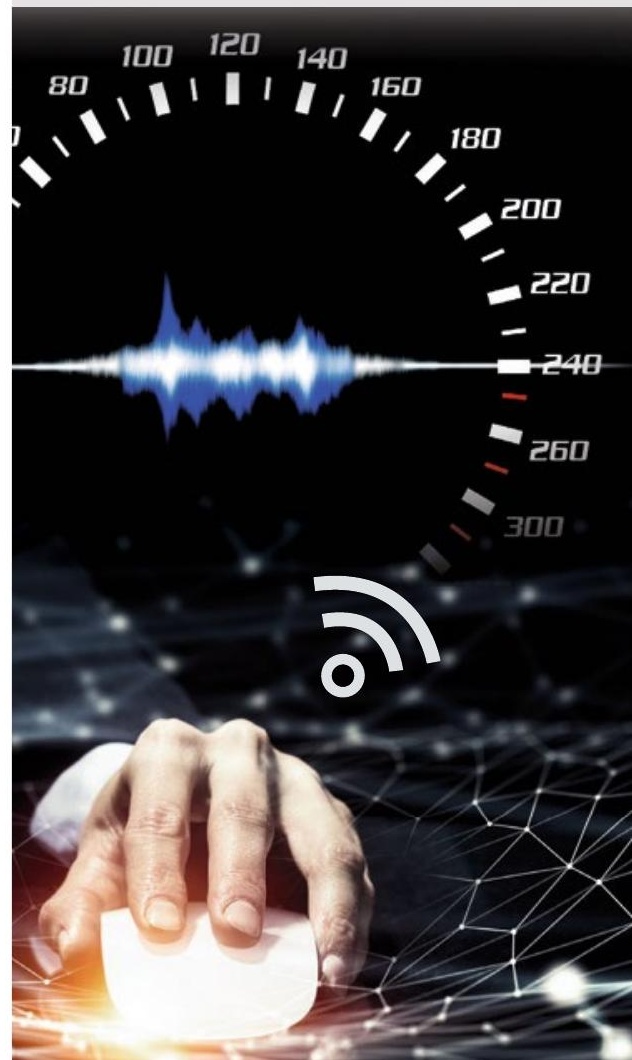

